Case Report

\title{
Rare case of chronic suppurative otitis media with gradenigo syndrome
}

\author{
Shiffali*, Priyanka, Kulwinder Singh Sandhu, Jagdeepak Singh
}

Department of Otolaryngology, Government Medical College, Amritsar, Punjab, India

Received: 27 April 2017

Accepted: 19 May 2017

\author{
*Correspondence: \\ Dr. Shiffali, \\ E-mail: dr.shiffali@gmail.com
}

Copyright: (C) the author(s), publisher and licensee Medip Academy. This is an open-access article distributed under the terms of the Creative Commons Attribution Non-Commercial License, which permits unrestricted non-commercial use, distribution, and reproduction in any medium, provided the original work is properly cited.

\begin{abstract}
We report a case of sixth nerve palsy as a rare complication of acute otitis media (apical petrositis). The clinical triad of symptoms consisting of retro-orbital unilateral pain related to trigeminal nerve involvement, diplopia due to sixth nerve palsy and persistent otorrhea is known as Gradenigo syndrome. The patient was treated with intravenous antibiotics along with modified radical mastoidectomy and had complete resolution of his symptoms.
\end{abstract}

Keywords: Apical petrositis, Gradenigo syndrome, Petrous bone

\section{INTRODUCTION}

Gradenigo syndrome consists of a triad of symptoms consisting of retro-orbital unilateral pain related to trigeminal nerve involvement, diplopia due to sixth nerve palsy and persistent otorrhea, associated with bacterial otitis media with apex involvement of the petrous part of the temporal bone. ${ }^{1}$ The clinical picture is of general interest, as the pain is in the form of a trigeminal neuralgia, except that it is limited to the first division of the fifth nerve and may persist for weeks or months after the discharge from the ear has ceased. It is also important to recognize the ocular palsy, which usually occurs between the fourth and sixth weeks, as a part of the same picture, and to know that.

\section{CASE REPORT}

A 12 year male child presented to ENT OPD of Govt. Medical College, Amritsar with history of otorhea from left ear foul smelling, occasionally blood stained, unilateral headache for 9 days localized to the left frontal and infraorbital area. History of inability of lateral movement of left eye along with diplopia in a primary gaze position that worsened when looking to the left side. Past history of recurrent otitis media. The left abducens nerve palsy was confirmed by Lancaster test. Fundus was normal in both eyes. Visual acuity was normal in both eyes. Tympanic membrane- attic area was seen full of granulations with pulsatile discharge left ear. No mastoid tenderness. Facial pain was distributed in the area of first and second branch of the left trigeminal nerve. No neck rigidity, Kernig's sign negative, No facial nerve paralysis signs, No fever. Motor function of Cranial nerves other than $6^{\text {th }}$ nerve was normal. Laboratory tests showed a white blood cell count of $14000 / \mathrm{mm} 3$, dlc$58 / 40 / 00 / 02 / 00$. All other blood investigations were within normal limit. Intravenous antibiotic treatment with amoxicillin-clavulanate (100 mg amoxicillin/ $\mathrm{kg} /$ day i.v.in two divided doses) was initiated, and changed to ceftriaxone (100 mg/kg/day i.v. in one dose)and metronidazole ( $35 \mathrm{mg} / \mathrm{kg} /$ day i.v. in three divided doses) as soon as the bacteriological results were known: the aural swab revealed a rich culture of S. Aureus. Dexamethasone $8 \mathrm{mg}$ bd i/v also started. Topically polymyxine $\mathrm{B} /$ neomycine ear drops were prescribed. A 
combined surgical and medical management was felt to be more appropriate than a purely medical treatment.

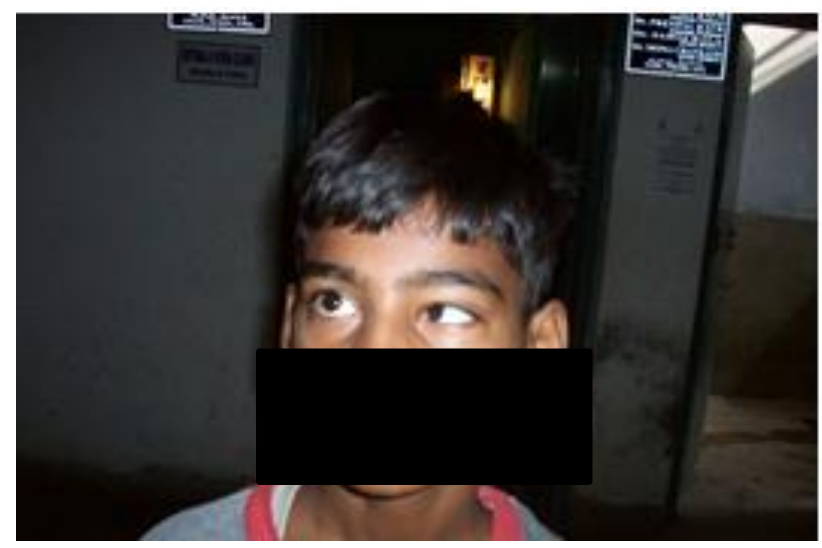

Figure 1: Pre-operative picture.

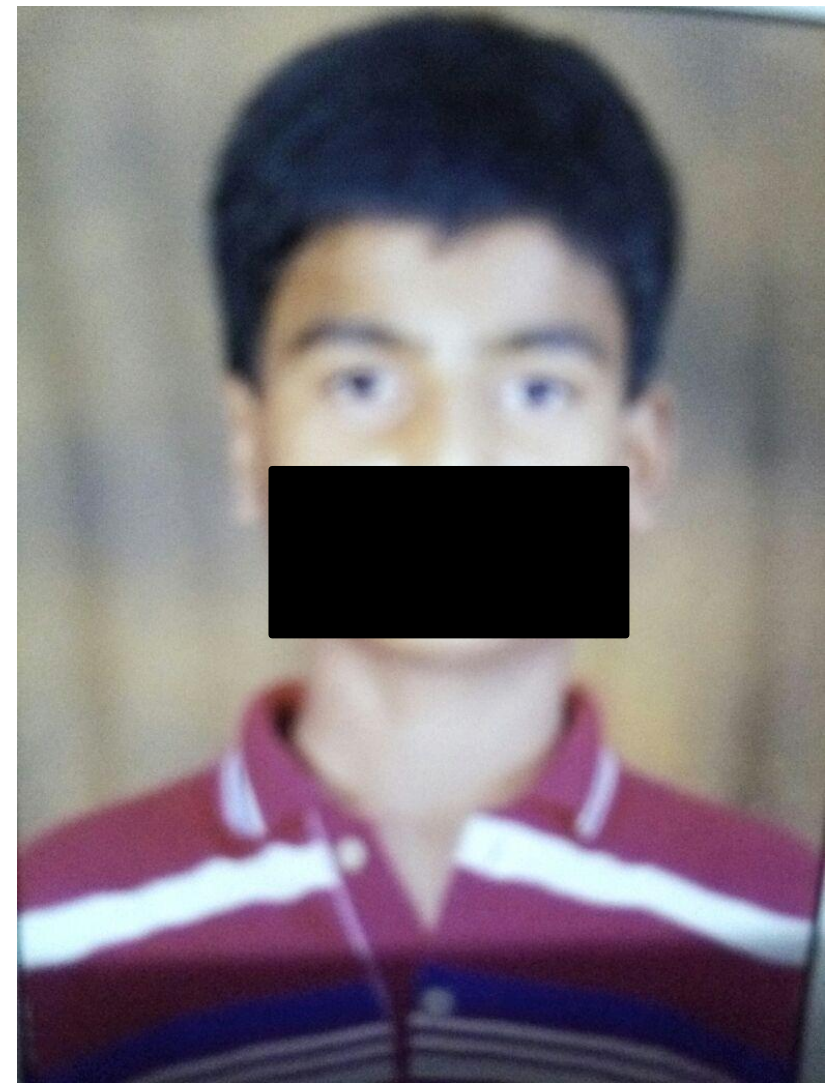

Figure 2: Present picture of the patient.

A modified radical mastoidectomy was thus performed. Peroperatively, middle ear cavity, aditus, and mastoid were found to be full of fleshy granulations and epitympanum had cholesteatoma present there. Ossicles, tegmen tympani and sinus plate were intact. Immediate post-operative period was uneventful. Gradual tapering of steroid was done over next 10days. Partial recovery of 6 th cranial nerve was noticed on $6^{\text {th }}$ postoperative day. On follow-up, 6 weeks after the surgical intervention, complete recovery of the abducens nerve palsy was noted. Further ophthalmological examination was normal. Audiometrical follow-up showed a normal hearing. Post operatively analgesics were stopped on $7^{\text {th }}$ day of operation with the patient being pain free most of the time. Now after 9 months of surgery the patient is symptom free with need of occasional cavity cleaning.

\section{DISCUSSION}

Gradenigo syndrome is due to the inflammation of the petrous apex of the temporal bone. Petrous apex is pneumatized in approximately $33 \%$ of patients. This absence of pneumatization is playing a role in the spread of infection. Additionally infection could also spread by direct extension or by hematological dissemination through the venous plexuses. ${ }^{2}$ Acute otitis media is a frequent childhood disease, with a potential for intratemporal and/or intracranial complications. ${ }^{3}$ With the advent of broad-spectrum antibiotics, the intracranial and intratemporal complications of infectious ear disease have become rare. ${ }^{4}$ Children younger than 11 years form almost $50 \%$ of the total number of patients with complications. ${ }^{5}$ The air cells in the petrous apex, which communicate with the middle ear, provide a route for spreading of infection and may cause petrositis, petrous apicitis, or otogenic cavernous sinus thrombophlebitis. ${ }^{6}$ Imaging techniques in otogenic intracranial complications are considered as important diagnostic assets. Although a contrasted head CT has high sensitivity for detection of inflammatory changes within the petrous apex, enhanced MRI is superior for detecting meningeal enhancement and other intracranial complications described above. A magnetic resonance venogram may also be performed to rule out comorbid venous sinus thrombosis which may occur as a complication of this entity. ${ }^{2,6-8}$ The management of Gradenigo syndrome includes medication, surgical, and conservative approaches. ${ }^{9,10}$

\section{CONCLUSION}

Gradenigo syndrome is a very rare but serious complication of acute otitis media and should be suspected in the presence of unilateral headache and abducens nerve palsy. It is most commonly caused by aerobic organisms but can result from infection with anaerobic organisms as in this present case. The management varies from radical surgery to conservative therapy depending on the clinical presentation. This patient recovered completely without sequelae after surgery and intravenous antibiotic therapy.

\section{Funding: No funding sources \\ Conflict of interest: None declared \\ Ethical approval: Not required}

\section{REFERENCES}

1. Gradenigo G. Uber die paralyse des n. Abduzens bei otitis. Arch F Ohrenheilk. 1907;74:149-58. 
2. Jacobsen CL, Bruhn MA, Yavarian Y, Gaihede ML. Mastoiditis and Gradenigo's Syndrome with anaerobic bacteria. BMC Ear Nose Throat Disord. 2012;12:10.

3. Kuczkowski J, Mikaszewski B. Intracranial complications of acute and chronic mastoiditis: report of two cases in children. Int $\mathbf{J}$ Pediatr Otorhinolaryngol. 2001;60:227-37.

4. Woody RC, Burchett SK, Steele RW, Sullivan JA, Mcconnell JR. The role of computerized tomographic scan in the management of Gradenigo's syndrome: a case report. Pediatr Infect Dis. 1984;3:595-7.

5. Albers FW. Complications of otitis media: the importance of early recognition. Am J Otol. 1999;20:9-12.

6. Marianowski R, Rocton S, Ait-Amer J, MorisseauDurand M, Manach Y. Conservative management of Gradenigo syndrome in a child. Int $\mathbf{J}$ Pediatr Otorhinolaryngol. 2001;57:79-83.
7. Jackler RK, Parker DA. Radiographic differential diagnosis of petrous apex lesions. Am J Otol. 1992;13(6):561-74.

8. Kantas I, Papadopoulou A, Balatsouras DG, Aspris A, Marangos N. Therapeutic approach to Gradenigo's syndrome: a case report. J Med Case Rep. 2010;24:4:151.

9. Lattanzi S, Cagnetti C, Di Bella P, Provinciali L. Mystery Case: Cholesterol granuloma of the petrous apex in Gradenigo syndrome. Neurology. 2015;84(17):e122-3.

10. Favier M, Bessou P, Franco-Vidal V, Pédespan JM. Gradenigo syndrome and petrositis in a child. Arch Pediatr. 2015;22(3):283-6.

Cite this article as: Shiffali, Priyanka, Sandhu KS, Singh J. Rare case of chronic suppurative otitis media with gradenigo syndrome. Int J Otorhinolaryngol Head Neck Surg 2017;3:755-7. 